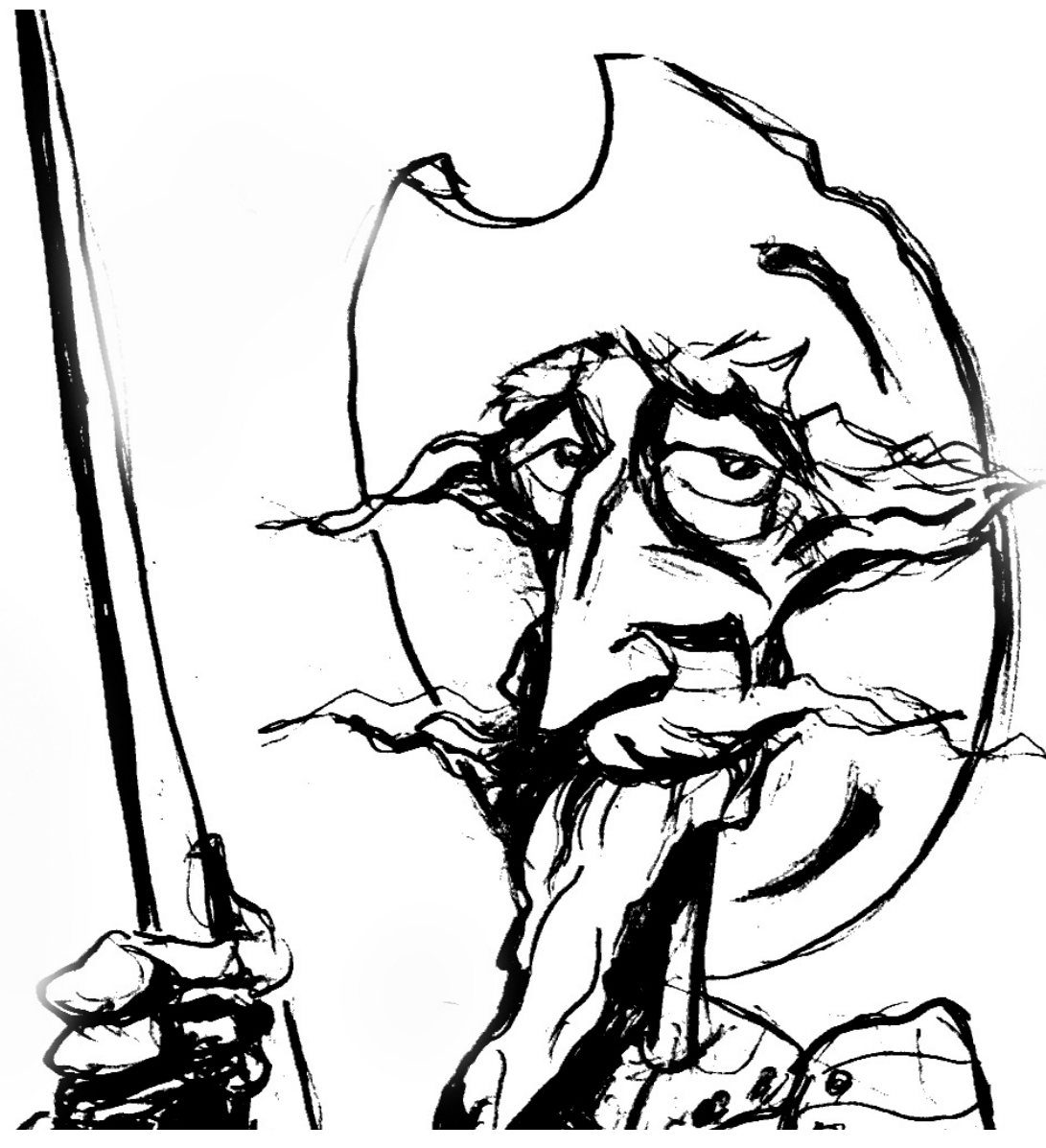

Un aviso ilustrado: el Informe de Jorge Juan sobre conveniencias e inconveniencias de un urgente asentamiento en las Islas del Atlántico Sur (11 de agosto de 1764)

[Darío G. Barriera] 


\title{
Un aviso ilustrado: el Informe de Jorge Juan sobre conveniencias e inconveniencias de un urgente asentamiento en las Islas del Atlántico Sur (11 de agosto de 1764)*
}

\author{
An Enlightened Notice: Jorge Juan's Report on the Conveniences and \\ Inconveniences of an Urgent Settlement in the South Atlantic Islands \\ (August 11, 1764)
}

DARÍO G. BARRIERA

\section{Resumen}

Durante la segunda mitad del siglo XVIII, Jorge Juan fue uno de los informantes más calificados para los circuitos cortesanos de Fernando VI y de Carlos III. Este informe, escrito 17 años después de los que había redactado con Antonio de Ulloa para el Marqués de la Ensenada publicados en Londres en 1826 como Noticias secretas de América...- es una pieza magnífica que retrata el tipo de actividad requerida al informante ilustrado en un contexto de crisis.

\begin{abstract}
During the second half of the 18th century, Jorge Juan was one of the most qualified informants for the courtesan circuits of Fernando VI and Carlos III. This report, written 17 years after the ones he had written with Antonio de Ulloa for the Marquis of the Ensenada -published in London in 1826 as Secret News of America...- is a magnificent piece showing the type of activity required of the enlightened informant in a critical context.
\end{abstract}

\section{Key Words}

Islas Malvinas; Spanish monarchy; Jorge Juan; Carlos III; Enlightenment

Islas Malvinas; monarquía española; Jorge Juan; Carlos III; Ilustración

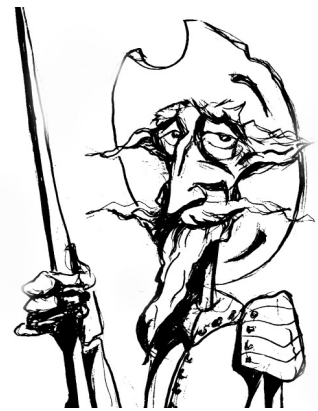

Recibido con pedido de publicación el 19 de enero de 2020 Aceptado para su publicación el 26 de febrero de 2020 Versión definitiva recibida el 30 de abril de 2020

Darío G. Barriera, Consejo Nacional de Investigaciones Científicas y Técnicas, Universidad Nacional de Rosario, Rosario, Argentina; e-mail: dgbarriera@conicet.gov.ar

* Este trabajo se inserta en el marco del PIP-CONICET 0326, del Programa MyAS (Malvinas y Atlántico Sur, Facultad de Humanidades y Artes de la UNR) y de la Red de Estudios sobre el Gobierno de Archipiélagos (RIESGA), con nodo sede en el mismo Programa. Agradezco las sugerencias recibidas y sobre todo la atenta lectura de Martín A. Gentinetta.

Esta obra se publica bajo licencia Creative Commons. Atribución-NoComercial-CompartirIgual 4.0 Internacional

Barriera, Darío G. “Un aviso ilustrado: el Informe de Jorge Juan sobre conveniencias e inconveniencias de un urgente asentamiento en las Islas del Atlántico Sur (11 de agosto de 1764)", Prohistoria, Año XXIII, núm. 33, jun. 2020, pp. 265275. 
Jorge Juan Santacilia nació el 5 de enero de 1713 en El Fondonet; fue bautizado en Monforte del Cid (Alicante) y falleció en Madrid 60 años después. Se formó en el Colegio de los jesuitas de Alicante bajo la tutoría de su tío Antonio Juan y luego cursó estudios en Zaragoza. En 1729 solicitó ingresar en la Real Compañía de Guardias Marinas en Cádiz. Al año siguiente ya revistaba en la Academia de esa Real Compañía, donde a causa de sus destacados conocimientos en matemáticas lo apodaron Euclides y "...cuando solo era un joven guardia marina de 21 años, junto con Antonio de Ulloa de 18 años, fue designado miembro de la expedición para medir el arco de meridiano", para lo que debió trasladarse a la Real Audiencia de Quito. (González Fernández, 2013: 253-254). Sus informes sirvieron para discutir la "esfericidad" de la tierra y para proponer la hipótesis del achatamiento en los polos.

Su estancia en América duró casi quince años. Una vez de regreso en la Península, fue ascendido al grado de capitán de navío. El marqués de la Ensenada -para quien habían redactado los informes junto con Antonio de Ulloa- lo envió en 1748 a Inglaterra, "...donde estudió y aprendió las técnicas navales más avanzadas, el resurgimiento de la Armada española en la segunda mitad del siglo XVIII. Para ello no dudó en traer a España cerca de un centenar de armadores y constructores de buques, que contribuyeron a su reconstrucción." (Trigo Chacón, 2013: 205).

En 1752, siempre bajo el ala política del marqués de la Ensenada, fue designado Director de la Academia de Guardias Marinas de Cádiz. Se trasladó a El Ferrol, desde donde puso en marcha la renovación de las técnicas de construcción naval en los astilleros peninsulares. A pesar de la caída de su protector político en 1754, su carrera en la Armada continuó, lo mismo que su cercanía al servicio del rey. Carlos III le encargó el Real Observatorio de Madrid (1757) y en 1760 fue designado jefe de escuadra de la Armada Real. El suyo fue el nombre más sonado cada vez que se mencionaba un posible desplazamiento de Julián de Arriaga -algo que, desde luego, no ocurrió- (Baudot Monroy, 2009: 254).

Es mucho lo que se ha estudiado sobre la contribución de Jorge Juan al mundo científico de su época y al desarrollo de lo que hoy llamaríamos "ciencia aplicada", de gran valor para el desarrollo de la navegación -comercial y de guerra-, actividades íntimamente ligadas con la conducción política de la monarquía. ${ }^{1}$ Incluso se han relevado y analizado sus vínculos con instituciones

1 Reseñar los estudios sobre la obra de Jorge Juan (con y sin Antonio de Ulloa) podría llevar varias páginas; es una figura de primer orden en los estudios sobre historia de la ciencia de la Ilustración y también de la relación entre los ilustrados y América -por ej. Martínez Almira, 2006: 128-153. Solo quería agregar que, alrededor del tercer centenario de su nacimiento en 2013, se hicieron varios coloquios y, en los años siguientes, se publicó un número mayor de estudios, como sucede al calor de ese tipo de coyunturas. Por ejemplo AAVV, 2017 o las Jornadas 
y figuras clave del universo político, en ocasiones conflictivos. Entre las más tirantes y complejas sobresale la relación que mantuvo con Julián de Arriaga, cuya trayectoria e implicancias han analizado María Baudot Monroy (2017) y Francisco Andújar Castillo (2017), entre otros. ${ }^{2}$ Los episodios relativos al final de su vida, esto es, su papel al frente del Seminario de nobles, su muerte y su herencia -material e intelectual- fueron también objeto de un abordaje colectivo de muy buena factura (Die Maculet y Alberola Romá, 2002).

La transcripción que volvemos ahora accesible en línea interesa, entonces, en primer lugar, por la catadura del autor del documento, por el sitio que Jorge Juan seguía ocupando entre los informantes más atendidos en el circuito cortesano y por el monarca en persona. Escrito 17 años después de los materiales que habían redactado conjuntamente con Antonio de Ulloa para el Marqués de la Ensenada -que se dieran a conocer públicamente en Londres en 1826 bajo el morboso título de Noticias secretas de América...- (Juan y Ulloa, 1826) el presente informe se ubica por partida doble en un contexto similar al de aquellas Noticias... Por un lado porque es un informe reservado; por el otro, porque lo redacta a la salida de una guerra con Inglaterra (la del Situado en el primer caso, la de los Siete Años, en el caso que nos ocupa).

En segundo lugar, en lo que atañe al tema de mis investigaciones sobre el gobierno del Atlántico sur y, más específicamente el de las islas, es un documento sobresaliente porque en él pueden leerse algunas ambigüedades sobre Malvinas que no provienen exclusivamente de lo que podríamos denominar, con los significados de la época, una perspectiva científica: su transcripción in extenso permite respaldar documentalmente una posición que es política antes que científica. Pero antes que científica no significa que su carácter científico sea secundario o que pase desapercibido. La perspectiva de Jorge Juan es a pesar de cualquier yerro científica porque esa es la calificación con la cual el informante es interpelado y porque existen numerosas marcas en el texto que aluden a esa identificación que hace de sí mismo como científico para su mandante. Nótese que lo primero que hace es comunicar a Arriaga cuánto lamenta "...vivir separado del mayor numero de mis libros y papeles, que siempre son precisos para satisfacer à muchos de los expedientes que v.e. se sirve comunicarme", poniendo negro sobre blanco cuáles son sus armas preferidas.

Jorge Juan, realizadas por la Real Academia de Ciencias Exactas, Físicas y Naturales en 2015 y publicadas en 2016. La revista general de Marina le dedicó su Tomo 265, publicado en agosto-sept. de 2013.

2 Andújar (2017: 324) coloca estos conflictos más allá de los planos interpersonales y postula que en Ejército y Marina $\mathrm{A}$ "...los estudios y los conocimientos científicos estuvieron postergados por unas estructuras vetustas que tan solo reconocían principios que se habían mantenido inamovibles desde siglos atrás." 
El tercer punto de interés de la publicación de la fuente viene a cuento del parafraseo de este texto que hace Ángela Domingues (2017) y de cómo echa en falta una buena fuente sobre el viaje de Bougainville, lo cual claramente le hubiera permitido despejar por ejemplo la cuestión de la presencia o ausencia de leña en las islas. Eso ilustra el déficit empírico sobre el cual Jorge Juan edificó su mirada experta, pero -todavía más importante- cuán consciente era del mismo: deslizando su acendrada adhesión a los por entonces novedosos criterios de erudición y documentación científica, es esa una afirmación que hace por terceros -la frase comienza con un conveniente "Dicen los Autores..."-. Tampoco se demora en dejar sentado que no tiene cómo validar el (recentísimo) viaje de Bougainville sobre el cual, se lamenta, no puede hacer otra cosa que "darlo por cierto". Esas son algunas de las huellas que dejan al descubierto al científico que hace el inventario de sus fuentes de información, las clasifica y, por cierto, como en este caso, lamenta no tenerlas.

Sin embargo, y como se advertirá con facilidad durante la lectura del informe, la posición que adopta Jorge Juan en su respuesta a Arriaga no requiere del conocimiento científico como un elemento indispensable. Lo que recomienda hacer al respecto de las islas se basa en una sensibilidad categóricamente política -desarrollada durante más de 20 años al servicio de la Corona- sin que, insisto, esto impidiera que sus receptores consideraran su informe como una respuesta científica.

La historia de mi relación con el documento es la siguiente: Ricardo Caillet Bois (1982: 96) transcribió un fragmento muy pequeño de este informe en una cita a pie de su obra Una tierra argentina, pero el autor de este gran libro no había dejado allí ninguna pista sobre su ubicación archivística. Esa fue mi primera referencia. Poco tiempo después lo encontré en una compulsa que realicé durante 2018 en el Archivo General de Simancas. Enseguida conocí la mención de Ângela Domingues, que glosa el contenido del informe y cita una versión alojada en el Archivo del Museo Naval de Madrid, España, dentro de una carpeta titulada Varios papeles del Sr. don Jorge Juan que bajo una carpeta con este título se encontrara en el despacho del Snr. Don Guillermo de Aubarede, a su fallecimiento en Octubre de 1850, Director que fue de este Depósito Hidrográfico, Madrid, 17 de Octubre de 1856, Ms. 0812 (Domingues, 2017: 110). ${ }^{3}$ Finalmente, después de haberlo transcripto en el Archivo General de Simancas, accedí a la versión completa que el mismo Caillet Bois transcribió en su Colección de documentos relativos a la historia de las Islas Malvinas, editada por la UBA en 1957 (Tomo I, entre las pp. 71 y 73), lo que de todos modos no me hizo desistir de esta publicación porque el valor del texto amerita su estudio preliminar y

3 Domingues retoma el contenido y alude a la existencia de "leña" en las islas... -algo que, desde los testimonios coetáneos de M. de Bougainville y su cronista, Antoine Joseph Pernety (Dom Pernety), sabemos errado-. 
porque su puesta en línea permitirá que el mismo sea aprovechado por usuarios de transcripciones como esta desde cualquier lugar del planeta.

No me extiendo en el análisis del rico contenido del texto, sobre el cual hago varias entradas en otra publicación en curso, y paso a ofrecer una transcripción literal y textual del documento, cuyo original consta de tres pliegos de 2 fojas sin foliar, escritos sobre verso y recto. Los números entre corchetes son para organizar la transcripción, mientras que [v] expresa como siempre vuelta de página. Los números "2" y "3" que figuran como parte del texto son los únicos que aparecen en el original, para señalar el inicio del $2^{\underline{o}}$ y del $3^{\text {er }}$ pliego respectivamente. La última, identificada aquí con el [6] es una foja suelta.

Informe de Jorge Juan a Julián de Arriaga, Madrid, 11 de agosto de 1764.

Archivo General de Simancas, España.

Descripción del catálogo según J. Paz y R. Magdaleno: Documentos relativos a Inglaterra, 1254-1834, edición y prólogo del Duque de Alba, AGS, Catálogo, XVII, Madrid, 1947.

Signatura actual: AGS, Estado, 6957, sin número de legajo.

[1]

Exmo. Sr.

Mui Sr. mio: la continuacion de marchas, y el grande envarazo en los transportes, me obligan á vivir separado del mayor numero de mis libros y papeles, que siempre son precisos para satisfacer à muchos de los expedientes que v.e. se sirve comunicarme: de este tenor es el adjunto extracto, qe restituyo à V. E; pero creerè que sin embargo de no poder presitualizar con fechas precisas, y Autores expressos, podrè cumplir con la orden que V. E. se sirve comunicarme, sin que quede duda

[v] sobre el principal fin à que se dirixe. Supongo para esto como cierto el hecho del viaje de $\mathrm{M}$. Bougainville, y su destino à formar un establecimiento, pues para ello basta creer su expedicion secreta. Si à mas de esto, se asegura que dho Bougainville aportò ${ }^{4}$ à Montevideo, no queda duda en que sus intenciones son de establecerse en las Islas proximas pa los estrechos de Magallanes, ò del Maire, ${ }^{5}$ passos precisos para la Mar del Sur; pues aunque assi mismo pudiera creerse poder ser en qualquiera de los Puertos de

$4 \quad$ En el sentido de "hacer puerto", admitido por Covarrubias y el Diccionario de autoridades antes de la redacción del texto.

5 Se refiere al Estrecho de Le Maire, que separa la isla de Tierra del Fuego de la Isla de los Estados. 
la Costa de los Patagones, como por exemplo la Bahia de Sn Julian, esta costa es sumamente

[2] àrida, y apenas se halla en ella Agua. Que sea esta la intencion se prueva, porque la navegacion à Montevideo està tan sumamente apartada de qualquier otro destino, y tan lexos los vientos de conducir à aquellos parages, que no puede dudarse un apice en la precisa Idea de dirigirse à ocupar alguna de aquellas tierras; pues ni aùn que vaya à la Mar del Sur puede creerse con solo su arribada à Montevideo, que aparta tanto la direccion. Esto senttado digo tambien que no puede la Francia pretextar, ni aùn con media apariencia poderle servir ningun establecimiento en las Islas Malvinas

[v]

para su comercio con la India oriental; puesto que aùn la Punta mas oriental, ò proxima de Dhas Islas se aparta de la carrera que se sigue en dicho comercio de mil leguas. Por este motivo, y no habiendo otro fin alguno que conduzca à semejante proceder, es sabido que los establecimientos en semejantes Islas no se han empreendido jamas, si no con la Idea de establecer un Puerto de arrivada à los Navios que fueren à la Mar del Sur.

Fue el primer movil para impedir à fines del año 49, ò principios de 50, igual empresa à los Ingleses, pues hallandome de orden del Rey en Londres, pude averiguar que muy

[3]

2 .

secretamente se armaban las dos Fragatas el Anson y el Porcopin à direccion del Almirante Anson, cuyas intenciones siempre fueron establecerse no solo en dichas Islas, si no en las costas de Chile: di aviso de esta mi sospecha y recelo al Sr. Dn. Ricardo Wall, que à la sazon se hallaba de Ministro Plenipotenciario en aquella Corte, quien dirigiendose con eficacia al Ministro, supo la verdad del hecho: hizole presente lo poco que correspondia este proceder à la sinceridad con que se establecieron los tratados que se acababan de hacer, y à la amistad tan grande que se manifestaba; y aunque repitiendo que tenian derecho

[v]

de poderlo executar, se pudo conseguir, muy contra la voluntad del Almirante Anson, que se desestimasse y avandonasse la empressa. Dio parte sin embargo al Rey el Sr. Dn Ricardo, y tambien la di yo, y se nos encargaron los mayores cuydados sobre el assunto; pero no hubo despues motivo de disgusto. La Francia supo passados algunos meses, estas Ideas, y las mirò con el mayor 
celo y cuydado; pero habiendosele informado lo sucedido quedò satisfecha. Todo esto debe constar en las Secretarias de Estado ú de Marina. no me parece necessario ponderar à V. E. el grandissimo daño que se nos siguiera de igual

establecimiento, pues aùn siendo por los Franceses, quien les cortaria el ilicito comercio en la Mar del Sur? Si estos se establecieran solo pr derecho de descubridores, ò por otros no menos mal fundados, lo mismo pretendieran los Ingleses, por que aquellas son una multitud de Islas descubiertas por varios Navios de las dos Naciones en distintos tiempos, y aùn esparcidas en varias Latitudes y Longitudes, sin que se conozcan aùn todas, habiendo algunas que solo los Ingleses han visto, como por exemplo la Isla de Pepys, que el Planito de V.E. llama Pepiis I, à la qual se dirigian las instancias del Almirante Anson

[v]

como mucho mas còmoda por su temperamento que las Malvinas, llamadas assi por los Franceses de St. Maló que aportaron à ellas. En unas y otras de estas Islas dicen los Autores que hay Agua, Leña, Pescado, y aùn muy buenas ensenadas y Puertos, con qe en qualquiera de ellas se puede formar el establecimiento como se conceda. Si se les permite à los Franceses, yo no pongo duda que lo quieran igualmente los Ingleses, por alegar igual derecho: unos y otros seran perjuidicales; pero estos con el excesso de poder cometer mayores estragos.

No concibo utilidad en que nosotros nos adelantemos à formar el tal establecimiento,

[5]

3.

como dice el extracto: lo primero, por qe aunque nosotros tomemos posession de una Isla, no por esso quitaremos à los extrangeros el pretendido derecho de las otras, y mas estando algunas mas de cien leguas distantes entre si: lo segundo, porque la sal de Sn Julian, que tambien dice el extracto, es quasi ninguna, y la Pesca que pondera lo mismo: y lo tercero, porque la Navegacion en derechura à Philipinas por aquellos parages es casi meramente imposible, sin la arribada à los Puertos del Peru.

Si un solo establecimiento nos fuera absolutamente inutil para estos fines, mucho mas

[v]

lo fuera la pluralidad que propone el extracto, pues por mas lugares que se ocuparan, muchos mas hubiera que ocupar, y con 
uno solo que les quedara à los extrangeros, bastara para que todo nos fuera inutil en el assunto.

No por esto me aparto de creer que para la conveniencia de nuestro comercio à la Mar del Sur, y para la de nuestras esquadras que hubieren de ir à ella, se hace ya quasi preciso, por que en Navegacion tan larga no es estraña una arribada, y de hacerla à un Puerto colocado en el mismo camino, ò à otro que se halle

[6]

extraviado hay gran diferencia, como à V.E. consta.

Por otro lado, quasi es imposible que el Rey pueda defender aquellos parages, y particularmente sus dominios en los Reynos de Chile y el Perù, si no con esquadras que con anticipacion vayan desde estos Reynos: lo primero porque sus costas son inmensas, y el numero de sus Puertos quantiosos, habiendo poca, ò quasi ninguna resistencia en ninguno de ellos; y lo segundo, por que qualesquiera defensas que alli se dispongan, sease por tierra y mucho mas por mar, son de cosos inmensos. Nuestras esquadras

[v]

en la Mar del Sur, aunque de iguales fuerzas, son ventajosas, por que de sus males se pueden reparar, lo que no los enemigos por falta de Puerto y aùn de materiales.

Todo esto pide premeditacion con tiempo; pero por lo presente siempre conviene oponerse à qualquier establecimiento que los extrangeros quieran hacer en las Islas Malvinas, Sebaldas, de Pepys, ù otras qualesquiera de las muchas que hay proximas al estrecho del Maire, à fin de precaber nuestro comercio, y lo que es mas, evitar que los Ingleses

[6]

lo quieran tambien executar. Este ultimo argumento puede servir mucho para qe los Franceses se contengan, y aùn no dudo qe haciendoles presentes que ya lo quisieron executar aquellos y se les contubo, resuelvan abandonar lo empreendido.

Nro sr. guarde a V.E. los ms años que necessita la Monarquia. Madrid, 11 de agosto de 1764.

Exmo. Sr.

$\mathrm{BM}^{\mathrm{o}}$ de V.E.

su ms. ren ${ }^{\text {o }} \operatorname{seg}^{\text {o }}$ serv $^{\text {or }}$

Jorge Juan

Lugar y fecha de finalización del artículo: Rosario, 30 de abril de 2020 


\section{Bibliografía}

AAVV (2017). Jorge Juan y la Ciencia Ilustrada, Madrid: Ministerio de Defensa de España.

Andújar Castillo, Francisco (2017). "Jorge Juan en el contexto de la Marina del siglo XVIII", en Alberola Romá, Armando; Cayetano Mas Galván y Rosario Die Maculet, Jorge Juan Santacilla en la España de la Ilustración, Alicante: Univ. de Alicante/Casa de Velázquez, pp. 303-324.

Baudot Monroy, María (2009). "La imagen de Julián de Arriaga como secretario de Marina. Algunos testimonios", en Martínez Shaw, Carlos y Alfonso Mola, Marina -coords.- España en el comercio marítimo internacional (siglos XVII-XIX). Quince estudios. Madrid: UNED, pp. 249-287.

Baudot Monroy, María (2017). "Jorge Juan y Julián de Arriaga: una relación difícil", en Alberola Romá, Armando; Cayetano Mas Galván y Rosario Die Maculet, Jorge Juan Santacilla en la España de la Ilustración, Alicante: Univ. de Alicante/Casa de Velázquez, pp. 279-302.

Caillet Bois, Ricardo (1982). Una tierra argentina. Las islas Malvinas, 3era edición, Buenos Aires: Academia Nacional de la Historia, [1era ed., 1948].

Die Maculet, Rosario y Alberola Romá, Armando (2002). La herencia de Jorge Juan. Muerte, disputas sucesorias y legado intelectual, Alicante: Univ. de Alicante.

Domingues, Ângela (2017). "Dominar el mundo a través de la ciencia: Imágenes de Brasil en la literatura de viajes en la segunda mitad del siglo XVIII", en Armando Alberola Romá, Cayetano Mas Galván y Rosario Die Maculet, Jorge Juan Santacilla en la España de la Ilustración, Alicante: Univ. de Alicante/Casa de Velázquez, pp. 109-122.

Gonzlez Fernández, Marcelino (2013). "Jorge Juan y la expedición para medir el arco de meridiano", en Revista General de Marina, ago-sept., vol. 265, pp. 253-272.

Juan, Jorge y Ulloa, Antonio de (1826). Noticias secretas de América sobre el estado naval, militar y político de los reinos del Perú y provincias de Quito, costas de Nueva Granada y Chile; gobierno y régimen particular de los pueblos de Indias; cruel opresión y extorsiones de sus corregidores y curas; abusos escandalosos introducidos entre estos habitantes por los misioneros; causas de su origen y motivos de su continuación por el espacio de tres siglos, Londres: edición de David Barry.

Martínez Almira, Ma. Magdalena (2006). "América en los informes de Jorge Juan", Canelobre, núm. 51, 2006, pp. 128-153. 